\title{
Aftas após instalação de aparelhos ortodônticos: porque isso ocorre e protocolo de orientações e condutas
}

\author{
Alberto Consolaro* e Maria Fernanda M-O Consolaro**
}

A palavra afta literalmente significa "eu inflamo", ou "eu ascendo" ou, ainda, "eu queimo". Inicialmente, foi utilizada na Grécia por Hipócrates, o pai da Medicina, para identificar o "sapinho" ou candidose pseudomembranosa em crianças. Mais tarde, seu uso se estendeu para toda e qualquer ulceração nas mucosas.

O termo úlcera deve ser reservado a lesões de superfície sem tendência à reparação depois de duas semanas, enquanto a palavra ulceração pode ser aplicada àquelas lesões com tendência ao reparo, como acontece com as aftas bucais.

\section{CLASSIFICAÇÃO DAS AFTAS BUCAIS}

As aftas podem ser classificadas em três tipos, de acordo com as suas manifestações e características clínicas:

1. Aftas menores, ou de Mickulicz: são ulcerações muito dolorosas ou ardentes, de $1 \mathrm{~cm}$ de diâmetro em média, e que afetam a mucosa bucal em áreas não queratinizadas (Fig. 1, 2). Podem ser únicas ou múltiplas, mas na maioria dos pacientes apresentam-se como lesões isoladas. Tendem à reparação, entre 5 e 10 dias, sem deixar cicatrizes.

2. Aftas maiores, ou de Sutton: são ulcerações maiores com extensões surpreendentes de até 3 a $4 \mathrm{~cm}$. São necrosantes, extremamente dolorosas, incapacitando o paciente para suas atividades normais. Sua duração, em média, se alonga entre 3 e 6 meses cada uma, deixando cicatrizes fibrosas e definitivas.

3. Aftas herpetiformes: caracterizadas pela multiplicidade de diminutas e dolorosas lesões ulceradas simultâneas na mucosa bucal. Esse nome resulta de sua semelhança com as lesões da estomatite herpética.

\section{AFTAS APÓS A INSTALAÇÃO DE APARELHOS ORTODÔNTICOS}

A instalação de aparelhos ortodônticos pode estar relacionada com o aparecimento de uma ou mais aftas na mucosa bucal, que quase sempre são lesões do tipo aftas menores, mas incomodam muito os pacientes, principalmente quando habitualmente não eram afetados por este problema antes da instalação dos aparelhos ortodônticos (Fig. 3).

Alguns pacientes apresentam as aftas no decorrer do tratamento e não necessariamente logo após a sua instalação. Esses casos podem estar relacionados a momentos de estresse físico ou psicológico, alterações de hábitos alimentares ou

\footnotetext{
* Professor titular em Patologia da FOB (graduação e pós-graduação) e da FORP (pós-graduação) - USP

** Professora doutora pela FOB-USP e ortodontista privada em Bauru.
} 


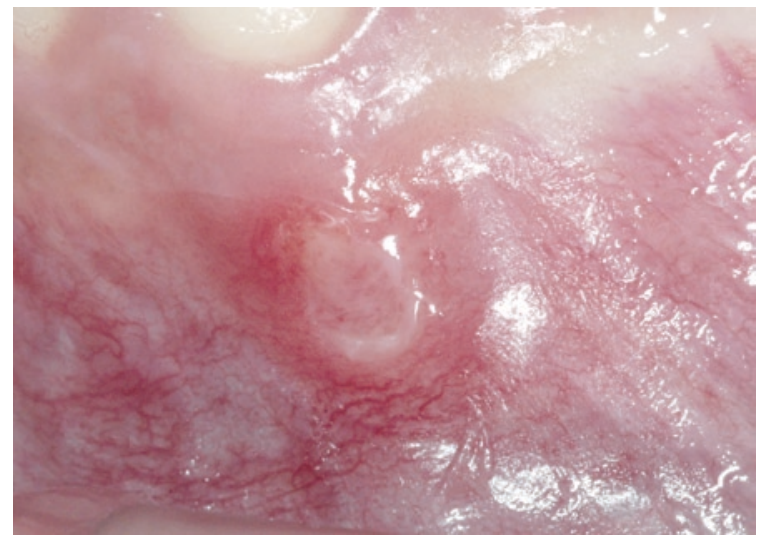

FIGURA 1 - Afta bucal menor em mucosa alveolar, caracterizada pelo leito recoberto por pseudomembrana constituída por fibrina e leucócitos polimorfonucleares que "protegem" o tecido conjuntivo exposto ao meio bucal. Circundando destaca-se o halo eritematoso típico dessa lesão muito sintomática.

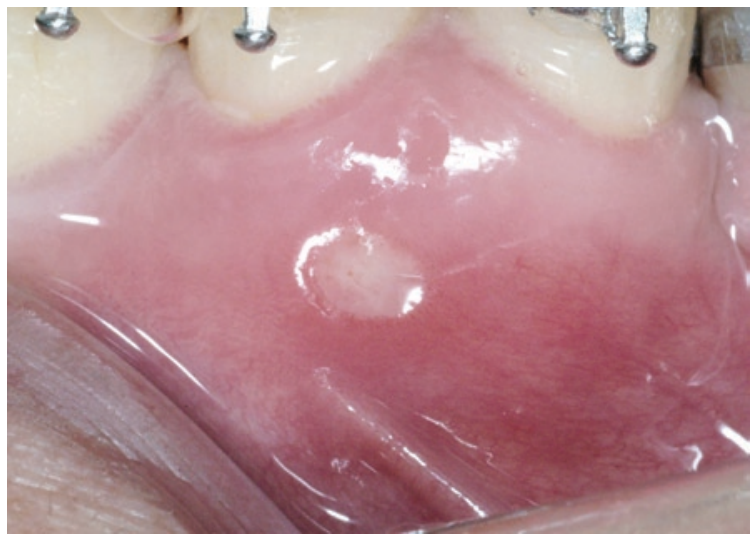

FIGURA 2 - Afta bucal menor em mucosa alveolar de paciente ortodôntico. Ao passar gel, pomada ou creme na lesão deve-se remover previamente a pseudomembrana para aumentar a penetração e 0 efeito dos medicamentos sobre o tecido conjuntivo subjacente, reduzindo-se a sintomatologia e o tempo de duração da lesão.

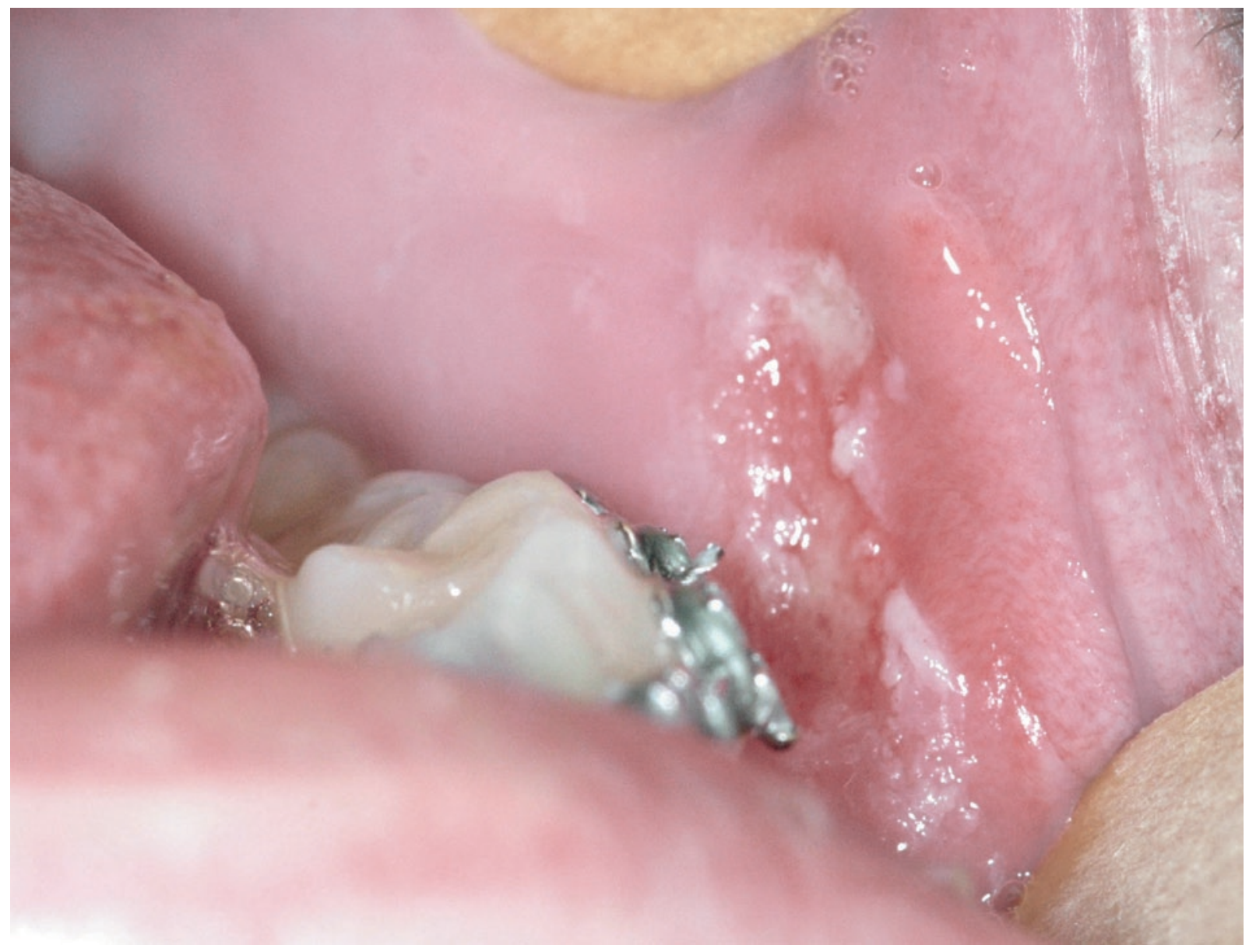

FIGURA 3 - Relação direta causa-efeito entre os acessórios ortodônticos indutores de microtraumatismos e a afta bucal modificada em seus aspectos clínicos mais clássicos pela lesão direta do traumatismo constante sobre a mucosa jugal. 
condições sistêmicas que possam modificar a reatividade do sistema imunológico.

Para compreender porque e como ocorrem essas situações clínicas na Ortodontia vamos discorrer, na forma de tópicos aparentemente independentes, sobre alguns pontos importantes na etiopatogenia das aftas bucais menores.

\section{Integridade da mucosa bucal e de sua queratinização}

As aftas bucais não ocorrem em mucosas queratinizadas, apenas em regiões com espessura epitelial menor e com superfícies sem camadas córneas ou, no máximo, discretamente paraqueratinizadas. O epitélio da mucosa bucal está separado e, ao mesmo tempo, isolado do tecido conjuntivo da submucosa pela membrana basal, pela qual ocorrem trocas metabólicas e se dá a integração estrutural e funcional.

A maior parte dos componentes imunológicos do organismo não interage com o tecido epitelial de forma direta, com exceção feita aos macrófagos intra-epiteliais, também conhecidos como células de Langerhans. Quando machucamos a mucosa bucal com alimentos, instrumentos, braquetes, escovas, agulhas ou outras formas, há uma exposição direta das células epiteliais ou queratinócitos para os componentes do tecido conjuntivo subjacente, inclusive os participantes da resposta imunológica.

Em pacientes fumantes, o aumento da espessura epitelial da mucosa bucal e de sua queratinização está presente em todas as regiões e esse tipo de paciente não apresenta aftas bucais em função dessa adaptação funcional induzida pelo tabaco. Quando pacientes fumantes deixam o vício, podem apresentar aftas, às vezes duradouras e múltiplas, e, em função dessa intercorrência, podem voltar a usar o tabaco.

Os pacientes com deficiência nutricional de vitamina $\mathrm{B}$ e de ferro apresentam anemia, pois estes são co-fatores importantes na proliferação das células na medula óssea produtora de hemácias.
Junto com a medula óssea, o revestimento epitelial da boca representa um dos tecidos mais proliferantes e renovados do nosso organismo, especialmente o dorso lingual. Da mesma forma que a carência nutricional desses dois fatores influencia na medula óssea, resultando em anemia, a mucosa bucal desses pacientes fica fina e menos ainda queratinizada, enfim, atrofiada. Muitos pacientes anêmicos também apresentam grande número de aftas bucais, pois, com a mucosa fragilizada, os microtraumatismos são mais freqüentes.

\section{Hereditariedade e aftas bucais}

A possibilidade de herdarmos a "capacidade" de ter aftas bucais é bem maior, ou quase absoluta, se os pais foram portadores de aftas ao longo da vida. Essa capacidade está associada à constituição da membrana das células epiteliais da mucosa bucal que, nesses pacientes, tem semelhança bioquímica com componentes da membrana de algumas bactérias que fazem parte da microbiota bucal.

Ainda é grande a chance, em torno de 50\%, de herdar-se essa capacidade se um dos pais apresentar essa propriedade. A possibilidade de herdar-se a característica de propensão às aftas é bem menor, ou muito reduzida, em filhos cujos pais não apresentam-se portadores ao longo da vida.

Em outras palavras, se os pais têm aftas, provavelmente os filhos também terão uma grande propensão a apresentá-las, pois suas células poderão ser reconhecidas como estranhas pelo sistema imunológico, tais como acontece com as dos pais. Quando o sistema imunológico reconhece que existem proteínas "bacterianas", ou melhor parecidas com as das bactérias, nas células epiteliais da mucosa, será desencadeado um mecanismo de auto-imunidade cruzada para destrui-las. Dessa forma, pontos focais da mucosa ficarão sem revestimento epitelial e as aftas aparecerão!

\section{Bactérias e as aftas bucais}

Algumas bactérias, especialmente estreptococos e estafilococos, podem apresentar componentes 
protéicos em suas membranas externas que se assemelham estruturalmente às proteínas das células epiteliais da mucosa bucal de algumas pessoas.

Como mencionado no tópico anterior, as características das células epiteliais são herdadas. Diariamente, o sistema imunológico produz mediadores, anticorpos e células sensibilizadas contra os componentes bacterianos e isso pode ser detectado medindo-se o nível plasmático de imunoglobulinas contra esses microrganismos. Em suma, em nosso organismo temos ferramentas celulares e bioquímicas para eliminar estreptococos e estafilococos que, por ventura, entrem na intimidade de nossos tecidos conjuntivos.

Se os componentes da membrana das células epiteliais são semelhantes aos de algumas bactérias da microbiota bucal, nosso organismo também estará apto a combater esses produtos "estranhos", ou "bacterianos", na superfície de nossas células. Se houver micro-ulcerações por traumatismos na mucosa bucal, nessas áreas o sistema imunológico reconhecerá que algumas células epiteliais, agora francamente expostas, deverão ser atacadas, por possuírem componentes estranhos na sua superfície. A necrose dessas células ampliará as microulcerações, que evoluirão para aftas bucais.

\section{Reação cruzada de auto-imunidade e as aftas bucais}

Quando, na mucosa bucal, ocorrem microulcerações induzidas por alimentos, instrumentos, braquetes, escovas, agulhas e outras formas, há uma exposição direta das células epiteliais ou queratinócitos para os componentes do tecido conjuntivo subjacente, inclusive os participantes da resposta imunológica.

Como os componentes do sistema imunológico estão prontos para atuar contra as bactérias da microbiota, tipo estreptococos e estafilococos, quando encontram proteínas semelhantes na superfície das células epiteliais da mucosa bucal, expostas ao conjuntivo pelos microtraumatismos, haverá uma reação de auto-imunidade cruzada.
As células epiteliais nas áreas microtraumatizadas morrerão e a ulceração se ampliará: assim se forma uma afta bucal. O que era uma simples perfuração de uma farpa de um abacaxi, ou de uma mordida acidental, evoluirá para uma afta bucal.

O processo cessará quando, depois de alguns dias, o sistema imunológico reconhecer, de forma mais refinada e molecular, que de fato as proteínas das células epiteliais da mucosa são semelhantes, mas não iguais, às das bactérias e não "mereciam" ser destruídas. Depois de 3 a 5 dias as aftas iniciarão um processo de reparação.

\section{Aftas bucais depois da instalação dos aparelhos}

Os braquetes, os fios e as bandas ortodônticas, uma vez instalados nos dentes, promovem invariavelmente microtraumatismos nos lábios, bochechas e margens linguais laterais, locais com revestimento epitelial paraqueratinizado (Fig. 3). Essa multiplicidade e continuidade de microtraumatismos sobre uma mucosa bucal delicada, em um organismo com propensão a ter aftas bucais por fatores hereditários, bacterianos e auto-imunes, explica porque isso ocorre, em alguns pacientes, algumas semanas após a instalação de aparelhos ortodônticos.

As aftas bucais após a instalação de aparelhos ortodônticos não decorrem de fatores alérgicos, não representam hipersensibilidade a componentes dos braquetes, fios e bandas. Uma vez transcorridas algumas semanas de uso do aparelho, haverá uma adaptação estrutural da mucosa bucal, que aumentará a espessura epitelial e a sua queratinização. As aftas diminuirão e até podem desaparecer por completo após esse período de adaptação, mas representam um grande incômodo clínico e pessoal.

\section{Estresse celular, quimioterapia, outras con- dições e as aftas}

O sistema imunológico tem sua função modulada por vários fatores. Algumas proteínas o 

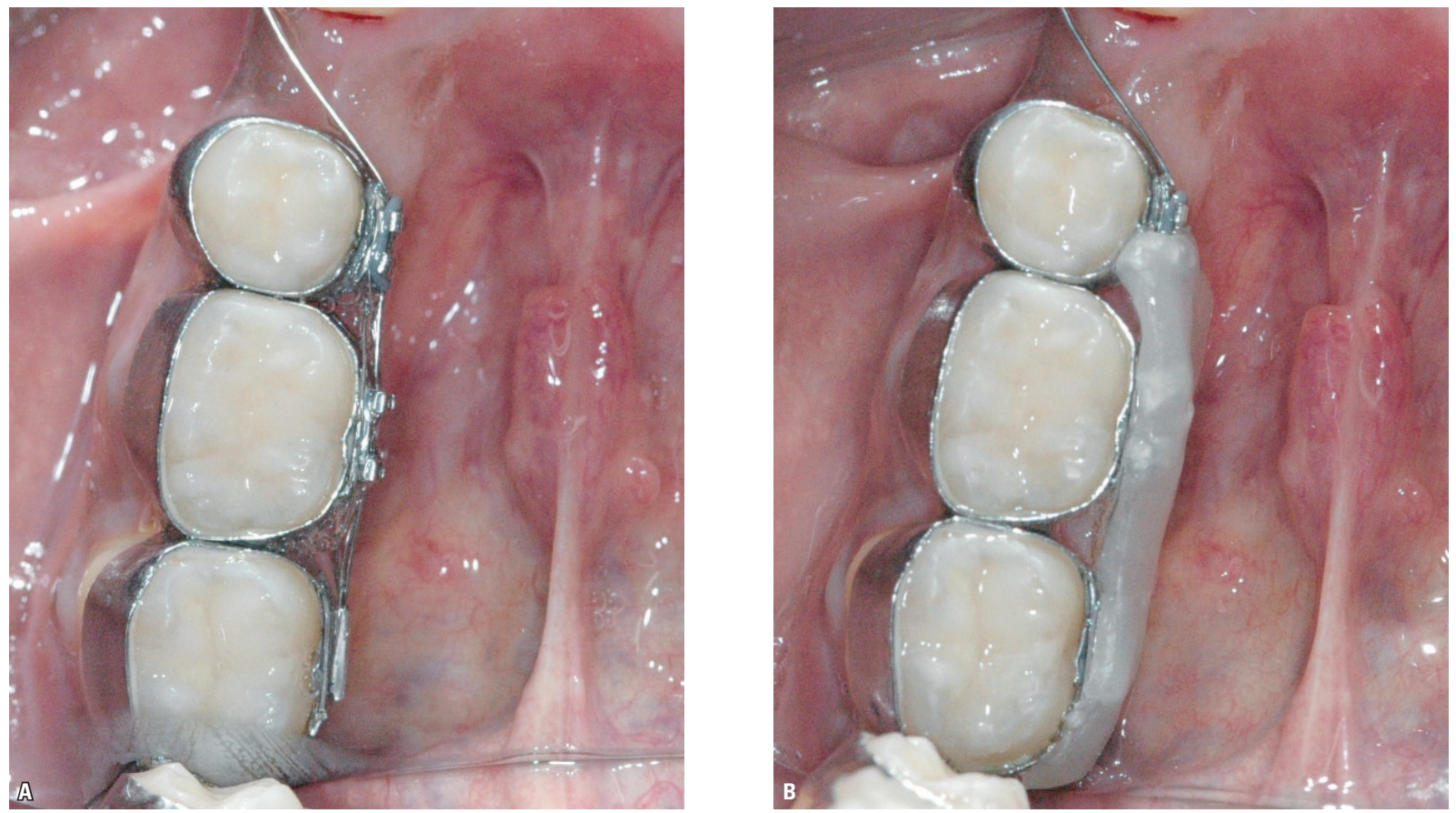

FIGURA 4 - Proteção (B) por oclusão das partes perfurantes e cortantes de braquetes, fios e acessórios ortodônticos (A) com cera específica, protegendo a língua e soalho bucal de micro-ulcerações importantes na etiopatogenia das aftas bucais. Os microtraumatismos seriam inevitáveis com a movimentação lingual e com a proteção haverá uma redução na possibilidade de aparecimento de aftas no local.

sistema imunológico aprendeu a tolerar, a aceitar como próprias do organismo. Outras ele reconhece imediatamente como estranhas. Esse equilíbrio de tolerância e de reatividade do sistema imunológico é modulado por mediadores e influenciado por várias condições de vida.

No estresse celular, os mediadores produzidos pela glândula supra-renal, ou hormônios, são produzidos em níveis modificados em relação ao normal, especialmente os produzidos em seu córtex. O nível alterado desses mediadores em condições de estresse altera o equilíbrio de tolerância e reatividade do sistema imunológico. Dessa forma, pacientes durante o tratamento ortodôntico podem, quase subitamente, apresentar-se com aftas bucais. Em condições de normalidade, o seu sistema imunológico não reconheceria as células epiteliais bucais como estranhas nos microtraumatismos, mas em condições de estresse passa a fazê-lo, determinando o aparecimento das aftas bucais. Assim pode ocorrer também em pacientes imunossuprimidos e nos submetidos à quimioterapia anti-neoplásica.

\section{ORIENTAÇÕES E CONDUTAS PARA PACIEN- TE ORTODÔNTICO COM AFTAS BUCAIS}

Em alguns pacientes ortodônticos, por maiores cuidados que sejam tomados - como a colocação de cera (Fig. 4) ou outro tipo de oclusão dos braquetes e fios para se evitar o contato e microtraumatismos na mucosa bucal -, as aftas bucais aparecem inevitavelmente em número maior do que o paciente estava acostumado. Mas deve-se orientar o paciente sobre como evitar os microtraumatismos durante:

1) a alimentação, para evitar alimentos perfurantes, como abacaxi, cascas de pão, pipoca e outros. Alimentos muito ácidos ou adstringentes 
podem alargar os microtraumatismos na mucosa bucal; recomendar a ingestão em forma de sucos ou cremes;

2) a higiene bucal, evitando o contato das cerdas e movimentos bruscos com as escovas sobre a mucosa bucal;

3) orientar sobre o uso de protetores sobre os braquetes, fios e bandas para evitar mordidas ao dormir, durante o apertamento bucal e o bruxismo;

4) afirmar ao paciente que, após algumas semanas de uso do aparelho, sua mucosa bucal se adaptará, aumentando a queratinização, e as aftas diminuirão ou provavelmente desaparecerão.

Um dos cuidados que se deve ter ao receber o paciente com aftas bucais mais freqüentes ou numerosas, após a colocação dos aparelhos ortodônticos, consiste em checar se o paciente tem mucosas coradas, se o mesmo se cansa facilmente ao menor esforço ou tem histórico de anemia carencial. Em caso de dúvida diagnóstica de anemia, recomendase uma avaliação por parte do médico da família ou a critério do paciente. Em geral, quando o quadro de aftas está associado ao de anemia, a correção do problema hematológico melhora considerável, ou totalmente, o quadro bucal.

Outro cuidado está em perguntar ao paciente se, simultaneamente à colocação do aparelho, abandonou o vício de fumar, o que pode ter agravado o quadro das aftas bucais. Esses aspectos devem ser explicados ao paciente.

A observação clínica e o estudo da composição dos remédios geralmente aplicados sobre as aftas bucais levaram-nos à formulação de um gel cujos princípios determinantes adotados foram: eficiência quanto ao alívio rápido da sintomatologia, baixa iatrogenia e conforto decorrente da facilidade de aplicação. $\mathrm{O}$ alívio imediato da sintomatologia local se faz muito importante, desenvolvemos, assim, um protocolo de condutas:

1) Limpar delicadamente o leito amarelado ou brancacento da afta (Fig. 1, 2) com cotonete umedecido em água oxigenada bem diluída ou em soro fisiológico, ou até em água. Esta pseudomembrana representa um obstáculo à penetração medicamentosa, mas nem sempre está presente.

2) Passar, por até cinco vezes ao dia, o gel formulado, receitando-o assim:

Uso tópico

Formular:

${ }^{*}$ Betametasona...................................... 0, $1 \%$

* Ácido acetilsalicílico.......................... 2,0\%

* Gel de hidroxipropilcelulose.............. 50g

Aplicar até cinco vezes ao dia, quando necessário, utilizando-se os dedos ou cotonetes levemente umedecidos.

3) Esclarecer ao paciente a finalidade do gel: apenas aliviar os sintomas e promover a sensação de conforto!

Esse gel tem fácil aplicação e pode ser usado isoladamente ou associado a tratamento sistêmico eventualmente administrado para aumentar a resistência do paciente às aftas ou para corrigir os fatores predisponentes à ocorrência das aftas na mucosa bucal, como as anemias. Os cuidados principais restringem-se às contra-indicações habituais para o uso de corticóides tópicos, como nos diabéticos, e orientações ao paciente para que não aplique o gel em excesso. Os três componentes do gel têm a finalidade respectiva de promover uma ação antiinflamatória, atuar como analgésico local e promover a formação de um filme provisório que retenha os medicamentos por alguns minutos ou horas sobre o leito da afta bucal, aliviando os sintomas da doença e reduzindo seu tempo de duração.

Outras pomadas, cremes e pastas com composições semelhantes também podem ser utilizados, seguindo o mesmo protocolo, mas em geral são de aplicação mais dificultada por parte do paciente. Recomenda-se não formular grandes quantidades desse gel, pois, após alguns meses de armazenamento, perde a transparência, adquire cor, fica consistente e reduz seus efeitos.

Em pacientes com aftas bucais do tipo maior, 
ou de Sutton, e do tipo herpetiforme, outros fatores podem estar envolvidos e requer-se uma abordagem mais detalhada do ponto de vista estomatológico. Ao ortodontista, recomenda-se encaminhar esses casos de aftas do tipo maior e herpertiforme para um clínico especializado experiente, visto que o seu aparecimento e evolução quase sempre independem da colocação do aparelho, constituindo apenas uma provável coincidência.

\section{QUESTIONAMENTOS FINAIS OU INSIGHTS}

No mercado ortodôntico, existem braquetes, fios e outros acessórios cujas margens, bordas, ângulos e extremidades são menos cortantes e perfurantes para que sejam indicados na instalação de aparelhos em pacientes com história pessoal e familiar de aftas bucais e/ou de outras situações mais delicadas da mucosa bucal?

Existem produtos confeccionados com material macio e flexível, tipo silicone, para os profissionais e pacientes aplicarem eficientemente como protetores em braquetes, cera, fios e acessórios para que possam "escondê-los" da mucosa bucal protegendo-a dos microtraumatismos, prevenindo-se aftas bucais?
Endereço para correspondência

Alberto Consolaro

E-mail: consolaro@uol.com.br 